\title{
Optimization of Milling Process by Taguchi-PSI Method
}

\author{
He Le Hoang Anh ${ }^{1}$, Trinh Kieu Tuan ${ }^{2}$, Nguyen Huu Quang ${ }^{2}$, Nguyen Huu Luan ${ }^{3}$, Tran Minh Truong ${ }^{4}$, and Nguyen \\ Thi Quoc Dung,"*
}

${ }^{1}$ Vinh Long University of Technology Education, Vietnam

${ }^{2}$ University of Economics - Technology for Industries, Vietnam

${ }^{3}$ Nguyen Tat Thanh University, Ho Chi Minh City, Vietnam

${ }^{4}$ Thai Nguyen University College of Economics and Techniques

${ }^{5}$ Thai Nguyen University of Technology, Thai Nguyen, Vietnam

\begin{abstract}
A4 steel (Chinese standard) is a steel with good machinability, which is very popularly used in mechanical engineering. Therefore, the study of solutions for improvement of quality and productivity when machining this steel type has great technical and economic significance. In this study, the multi-objective optimization process has been performed when milling this steel type on a vertical milling machine. The cutting tool is a face milling cutter made of High Speed Steel (HSS) material. The effect of spindle speed, feed rate, and cutting depth on surface roughness has been found. The combination of the Taguchi method and PSI method has been applied to determine the optimal value of three input parameters to simultaneously ensure the two criteria of the minimum surface roughness and the maximum Material Removal Rate (MRR). The works which will be done by the authors of this article in the near future has also been presented in the last part of this study.
\end{abstract}

\section{Introduction}

When milling the plane with a face milling cutter, the productivity is much higher than other milling methods because the face milling cutter has many teeth involved in cutting and it is possible to choose a milling cutter with a large diameter [1]. Surface roughness of the workpiece, and MRR are two of the parameters that are of special interest because the surface roughness is a parameter reflecting the surface quality, and the MRR is a parameter reflecting the machining productivity. Because of that, there has been a large number of studies looking for solutions to improve the surface quality and machining productivity, namely reducing surface roughness and increasing MRR. Among them, many authors have chosen the Taguchi method to design experiments.

A. A. Tharke [2] has designed the experimental matrix by the Taguchi method when milling 1040 MS steel. The surface roughness has been chosen by him as the output parameter. He has used signal-to-noise $(\mathrm{S} / \mathrm{N})$ ratio analysis to determine the value of cutting parameters, including cutting velocity, feed rate, and cutting depth, to ensure the minimum surface roughness.

M. Prakash et al. [3], when conducting the experiment of milling OHNS steel, have also designed the experimental matrix by Taguchi method. The three parameters have been also chosen by them as input parameters including cutting velocity, feed rate and cutting depth. The S/N ratio analysis has also been used by them to determine the values of input parameters to ensure the minimum surface roughness.

Manoj Kumar et al. [4] have also used the Taguchi method to design the experiments when milling D2 steel. The parameters have been chosen by them as input parameters also including cutting velocity, feed rate, and cutting depth. Then the $\mathrm{S} / \mathrm{N}$ ratio analysis method has been also chosen by them to determine two optimal sets of input parameters, one to ensure the minimum surface roughness and the other to ensure the maximum $M R R$. Many studies have also applied the Taguchi method to design experiments and $\mathrm{S} / \mathrm{N}$ ratio analysis method to determine two sets of parameters of cutting parameters for the purpose of simultaneously ensuring the two separate criteria of the minimum surface roughness and the maximum $M R R$, such as the study of P. V. Krishna et al. [5] when milling 6016 aluminum alloy, the study of S. S. Panshetty et al. [6] when milling 7076 aluminum alloy, the study of H. Shagwira et al. [7] when milling Polypropylene $+5 \mathrm{wt} . \%$ Quarry Dust Composites, the study of D. P. Vanish et al. [8] when milling Titanium alloy, etc.

From a number of the above studies, it is shown that the experimental design by Taguchi method and $\mathrm{S} / \mathrm{N}$ ratio analysis has been successful in a number of milling process optimization studies. However, the above studies also show a drawback that if only designing the experiment by Taguchi method and analyzing the results

\footnotetext{
* Corresponding author: quocdung@tnut.edu.vn
} 
by $\mathrm{S} / \mathrm{N}$ ratio, it is possible to achieve only one objective of milling process (either the minimum surface roughness or the maximum MRR). Therefore the combination of Taguchi $+\mathrm{S} / \mathrm{N}$ ratio analysis will not solve the multi-objective problem. In order to solve the multi-objective optimization problem, it is necessary to combine Taguchi with a certain mathematical method. Some methods have been very successful in solving the multi-objective optimization problem when it is combined with Taguchi method such as: Taguchi-Dear combination [9], Taguchi-Topsis [10-16], Taguchi-Vikor [17-19], Taguchi-Moora [20, 21], etc. PSI (Preference selection index) is also a method for multi-objective optimization and has been successfully used in combination with the Taguchi method in a number of studies such as: Multi-objective optimization in the design of production system [22]; Optimizing the criteria of computer software for human resource management [23]; Determining the best factors in choosing the location for sale of used computers (rental price, location, number of customers, ..) [24] etc. However, so far, there have been no studies combining the Taguchi and PSI in solving the multi-objective optimization problem of the milling process.

From the above analysis, in this study, the Taguchi method will be applied to design the experimental matrix when milling 060A4 steel. PSI method will be applied to solve the multi-objective optimization problem. The objective of this study is to determine the value of spindle speed, feed rate and cutting depth to simultaneously ensure the two criteria, including the minimum surface roughness and the maximum $M R R$

\section{PSI method}

PSI is a multi-objective optimization method is first introduced in 2010. This is an approach based on the concept of "overall preference value of attributes". The outstanding feature of this method is the optimization of the objectives without assigning weights to the criteria. This method is performed according to the following steps [25]:

Step 1: Determine the objectives.

Step 2: Create a decision matrix based on the available information.

Step 3: Normalize the attributes.

$N_{i j}=\frac{x_{i j}}{x_{j}^{\max }}$

$N_{i j}=\frac{x_{j}^{\min }}{x_{i j}}$

for benefitical type

Where: $i$ is the ordinal number of the row in the matrix $(i=1 \div n), j$ is the ordinal number of the column in the matrix $(j=1 \div m), x_{i j}$ is the value of the criterion in row $i$ and column $j$.

Bước 4: Calculate the average values of normalized data.

$$
N=\frac{1}{n} \sum_{i=1}^{n} N_{i j}
$$

Step 5: Determine the preferred values from the average values.

$\varphi_{j}=\sum_{i=1}^{n}\left[N_{i j}-N\right]^{2}$

Step 6: Determine the deviation in the preferred value.

$\emptyset_{j}=\left[1-\varphi_{j}\right]$

Step 7: Determine the overall preferred value for the criteria.

$w_{j}=\frac{\emptyset_{j}}{\sum_{j=1}^{m} \emptyset_{j}}$

Step 8: Calculate the preference selection index (PSI) of each solution.

$\theta_{j}=\sum_{j=1}^{m} x_{i j} \cdot w_{j}$

Step 9: Rank the solutions. Which solution that has the largest value of $\theta_{i}$ is the best solution.

\section{Experimental process}

060A4 steel has been used during the experiment. When analyzing the spectrum, the chemical composition of some elements of steel has been determined as shown in Table 1. This steel type has good machinability, low cost and it is the most popular steel type for manufacturing all kinds of common parts such as bearings, shafts, gears, grips [26].

Table 1. Chemical composition of 060A4 steel

\begin{tabular}{ccccccccccc}
\hline \multicolumn{10}{c}{ Composition (\%) } \\
\hline $\mathrm{C}$ & $\mathrm{Si}$ & $\mathrm{Mn}$ & $\mathrm{Cr}$ & $\mathrm{Ni}$ & $\mathrm{Mo}$ & $\mathrm{V}$ & $\mathrm{Ti}$ & $\mathrm{B}$ & $\mathrm{Cu}$ \\
0.4 & 0.2 & 0.6 & 0.2 & 0.1 & 0.0 & 0.0 & 0,00 & 0.000 & 0.2 \\
3 & 4 & 6 & 2 & 4 & 3 & 2 & 2 & 7 & 1 \\
\hline
\end{tabular}

A JLVH320B vertical milling machine has been used to conduct the experiments (figure 1). The feed rate of machine is calculated as the displacement of platform per a unit of time. The value of this parameter can be arbitrarily (steplessly) adjusted because it is controlled by the hydraulic pump system. The value of this parameter is selected through the rotation of crown in conjunction with the chronograph. The cutting depth is adjusted by the vertical vernier of machine, for each stroke of vernier, the cutting tool will move by $0.02 \mathrm{~mm}$. The milling machine has 24 values for the number of revolutions of the spindle. The adjustment of this value is made by means of grips. 


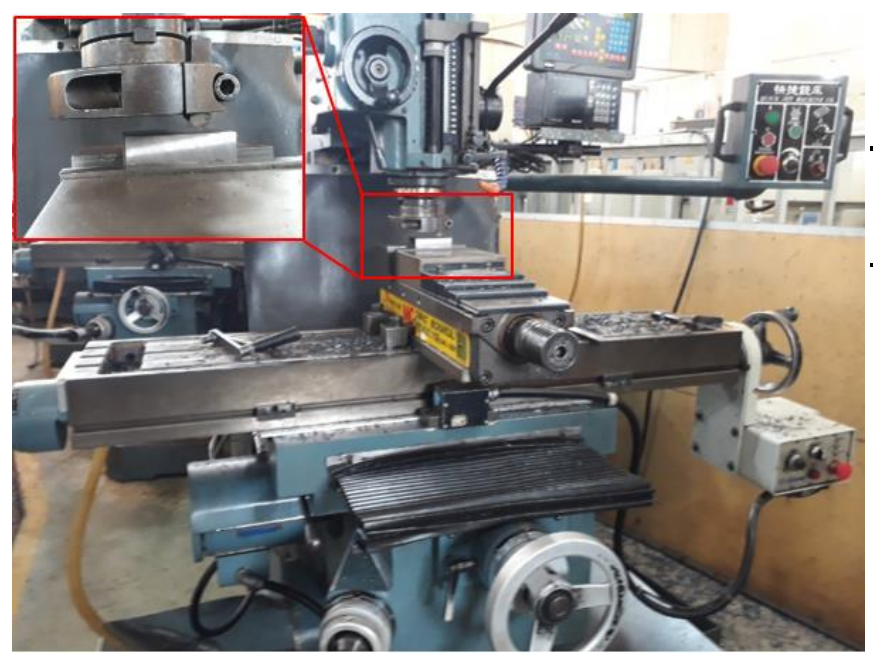

Fig. 1.JLVH320B vertical milling machine

The cutting tool material used in the experiment is HSS. This cutting tool has relatively high heat resistance, low cost, and good cutting performance, so it is widely used in milling [27]. The chip has been inserted into the body of the milling cutter with a diameter of $120 \mathrm{~mm}$.

The parameters including spindle speed, feed rate, and cutting depth have been selected as the three input parameters of the experimental process. These three parameters can all be adjusted quickly by the worker and have also been selected as the experimental input parameters in many studies [28]. The values of these parameters are chosen to be suitable when milling 060A4 steel with HSS cutting tools as well as suitable for the ability of their value adjustment of the experimental machine. Based on those bases, the values of cutting parameters are shown in Table 2.

Table 2. Cutting parameters

\begin{tabular}{|c|c|c|c|c|c|}
\hline \multirow{2}{*}{ Parameter } & \multirow{2}{*}{ Symbol } & \multirow{2}{*}{ Unit } & \multicolumn{3}{|c|}{ Value at level } \\
\hline & & & 1 & 2 & 3 \\
\hline Spindle speed & $n$ & $\mathrm{rev} / \mathrm{min}$ & 70 & 105 & 126 \\
\hline Feed rate & $V_{f}$ & $\mathrm{~mm} / \mathrm{min}$ & 538 & 788 & 1152 \\
\hline Depth of cut & $a_{p}$ & $\mathrm{~mm}$ & 0.4 & 0.6 & 0.8 \\
\hline
\end{tabular}

Taguchi method has been applied to design the experimental matrix. With the three input parameters and the three values for each, there are two options of the number of experiments, option 1 is nine experiments, and option 2 is 27 experiments. The essence of the option with 27 experiments is to repeat three times of the option with nine experiments. The purpose of choosing a matrix with 27 experiments is to reduce random error during the experiment. Howerver it is also because of the large number of experiments, it affects the time and cost of the experimental process. Therefore, in this study, the matrix with number of experiments equal to 9 has been chosen as shown in Table 3.

In order to reduce random errors during the experiment, the surface roughness has been measured at least three times for each sample; the roughness value at each experiment is the average value of measurements. For the $M R R$, this value is calculated in accordance with the formula (8), so it is not affected by the experimental process.

Table 3. Experimental matrix

\begin{tabular}{lllllll}
\hline \multirow{2}{*}{ No. } & \multicolumn{7}{c}{ Code value } & \multicolumn{7}{l}{ Actual value } \\
\cline { 2 - 7 } & $n$ & $f$ & $a_{p}$ & $n(\mathrm{rev} / \mathrm{min})$ & $f(\mathrm{~mm} / \mathrm{min})$ & $a_{p}(\mathrm{~mm})$ \\
\hline 1 & 1 & 1 & 1 & 538 & 70 & 0.4 \\
2 & 1 & 2 & 2 & 538 & 100 & 0.6 \\
3 & 1 & 3 & 3 & 538 & 130 & 0.8 \\
4 & 2 & 1 & 2 & 788 & 70 & 0.6 \\
5 & 2 & 2 & 3 & 788 & 100 & 0.8 \\
6 & 2 & 3 & 1 & 788 & 130 & 0.4 \\
7 & 3 & 1 & 3 & 1152 & 70 & 0.8 \\
8 & 3 & 2 & 1 & 1152 & 100 & 0.4 \\
9 & 3 & 3 & 2 & 1152 & 130 & 0.6 \\
\hline
\end{tabular}

Where $f, a_{p}, b_{w}$ are feed rate, cutting depth and cutting width, respectively. Because the milling cutter diameter is $120 \mathrm{~mm}$, while the workpiece width is only $40 \mathrm{~mm}$, the milling width is equal to the workpiece width, that is, $\mathrm{b}_{\mathrm{w}}=40 \mathrm{~mm}$

$\operatorname{MRR}=f \cdot a_{p} \cdot b_{w}\left(\mathrm{~mm}^{3} / \mathrm{min}\right)$

\section{Results and discussion}

The experiments have been conducted in the order as shown in Table 3, the results are presented in Table 4. In Figure 2, the Pareto chart shows the effect of input parameters on surface roughness, with the chosen significance level is 0.05 [29, 30]. Since the curve showing the effect of feed rate on surface roughness has passed the limiting curve in the Pareto chart (the limit value is 2.571), we can confirm that the feed rate has a great effect on the roughness. Meanwhile, spindle speed and cutting depth have an insignificant effect on surface roughness. However, if considered in detail, it is found that the cutting depth has an effect on the surface roughness being greater than the effect of spindle speed.

Table 4. Experimental results

\begin{tabular}{cccccc}
\hline No & $\begin{array}{c}\mathbf{n} \\
(\mathbf{r e v} / \mathbf{m i n})\end{array}$ & $\begin{array}{c}\mathbf{f} \\
(\mathbf{m m} / \mathbf{m i n})\end{array}$ & $\mathbf{a p} \mathbf{( m m )}$ & $\begin{array}{c}\mathbf{R}_{\mathbf{a}} \\
(\mathbf{m m})\end{array}$ & $\begin{array}{c}\mathbf{M R R} \\
\left(\mathbf{m m}^{3} / \mathbf{m i n}\right)\end{array}$ \\
\hline 1 & 538 & 70 & 0.4 & 0.51 & 1120 \\
2 & 538 & 100 & 0.6 & 0.73 & 2400 \\
3 & 538 & 130 & 0.8 & 0.59 & 4160 \\
4 & 788 & 70 & 0.6 & 0.38 & 1680 \\
5 & 788 & 100 & 0.8 & 0.42 & 3200 \\
6 & 788 & 130 & 0.4 & 0.76 & 2080 \\
7 & 1152 & 70 & 0.8 & 0.39 & 2240 \\
8 & 1152 & 100 & 0.4 & 0.62 & 1600 \\
9 & 1152 & 130 & 0.6 & 0.64 & 3120 \\
\hline
\end{tabular}




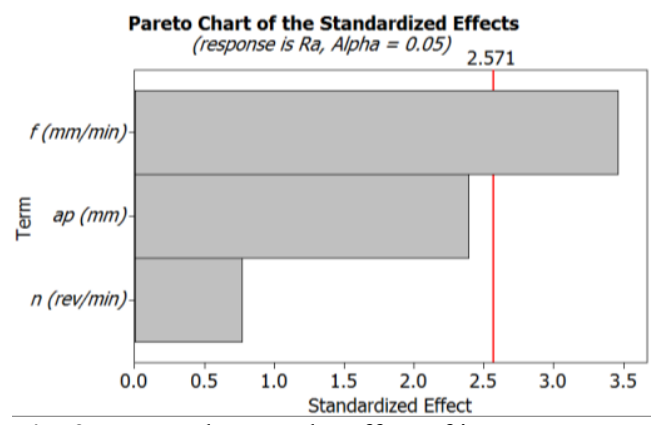

Fig. 2. Pareto chart on the effect of input parameters on surface roughness

With the data available in Table 4, it is shown that in experiment \#4, the surface roughness has the smallest value. However, also in this experiment, the MRR value is also quite small; it is only larger than the $M R R$ in experiments $\# 1$ and $\# 8$. Thus, experiment \#4 is surely not the best of the nine conducted experiments. In experiment \#3, the MRR value is the largest. However, the surface roughness in this experiment is still larger than the surface roughness in experiments \#1, \#4, \#5 and \#7. Therefore, we cannot say that the experiment \#3 is the best one. In order to have a solid basis for asserting which experiment is the best, it is necessary to draw conclusions on a solid mathematical basis. That is the reason why we need to solve the multi-objective optimization problem. This content will be presented in the next part of this article.

\section{Multi-objective optimization of milling process}

Step 1: The objectives of this study are determination of the best solution in the solutions as listed in Table 4. At that solution (experiment), $R a$ is considered "minimum" and MRR is considered "largest".

Step 2: Create a decision matrix based on the available information. From the data in Table 4, the last two columns in the table form a 9-row 2-column matrix, which is the matrix where we need to identify the row considered "best" in 9 rows.

Step 3: The standardized value of the attributes were calculated by Eq. (1) and Eq. (2), and presented as in Table 5.

Step 4: The average values of normalized data were calculated by Eq. (3). These values were also listed in Table 5.

Step 5: Determine the preferred values from the average values by Eq. (4): $\varphi_{\mathrm{Ra}}=0.29858 ; \varphi_{\mathrm{MRR}}=0.30843$

Step 6: Determine the deviation in the preferred value by Eq. (5): $\varnothing_{\mathrm{Ra}}=0.70142 ; \varnothing_{\mathrm{MRR}}=0.69157$

Step 7: Determine the overall preferred value for the criteria by Eq. (6): $\mathrm{w}_{\mathrm{Ra}}=0.50354 ; \mathrm{w}_{\mathrm{MRR}}=0.49646$.

Step 8: Calculate the Preference selection index $\theta$ (PSI) of each solution by Eq. (7). These calculated results were presents in Table 6.

Step 9: Rank the solutions as presented in Table 6.
Table 5. Standardzation value of the attributes

\begin{tabular}{|c|c|c|c|c|}
\hline No. & $\begin{array}{c}\mathbf{R}_{\mathbf{a}} \\
(\mathrm{mm})\end{array}$ & $\begin{array}{c}\text { MRR } \\
\left(\mathrm{mm}^{3} / \mathrm{min}\right)\end{array}$ & $\mathbf{N}_{\mathbf{R a}}$ & $\mathbf{N}_{\text {MRR }}$ \\
\hline 1 & 0.51 & 1120 & 0.74510 & 0.26923 \\
\hline 2 & 0.73 & 2400 & 0.52055 & 0.57692 \\
\hline 3 & 0.59 & 4160 & 0.64407 & 1.00000 \\
\hline 4 & 0.38 & 1680 & 1.00000 & 0.40385 \\
\hline 5 & 0.42 & 3200 & 0.90476 & 0.76923 \\
\hline 6 & 0.76 & 2080 & 0.50000 & 0.50000 \\
\hline 7 & 0.39 & 2240 & 0.97436 & 0.53846 \\
\hline 8 & 0.62 & 1600 & 0.61290 & 0.38462 \\
\hline \multirow[t]{2}{*}{9} & 0.64 & 3120 & 0.59375 & 0.75000 \\
\hline & Mean & & 0.718880 & 0.61538 \\
\hline
\end{tabular}

Table 6. Values of $\theta$ in PSI and ranking

\begin{tabular}{ccccc}
\hline No. & $\begin{array}{c}\text { Ra } \\
(\boldsymbol{\mu m})\end{array}$ & $\begin{array}{c}\text { MRR } \\
\left(\mathbf{m m}^{\mathbf{3}} / \mathbf{m i n}\right)\end{array}$ & $\boldsymbol{\theta}$ & Ranking \\
\hline 1 & 0.51 & 1120 & 556.29201 & 9 \\
2 & 0.73 & 2400 & 1191.87158 & 4 \\
3 & 0.59 & 4160 & 2065.57069 & 1 \\
4 & 0.38 & 1680 & 834.24415 & 7 \\
5 & 0.42 & 3200 & 1588.88349 & 2 \\
6 & 0.76 & 2080 & 1033.01949 & 6 \\
7 & 0.39 & 2240 & 1112.26678 & 5 \\
8 & 0.62 & 1600 & 794.64819 & 8 \\
9 & 0.64 & 3120 & 1549.27747 & 3 \\
\hline
\end{tabular}

From the ranked results in Table 6, it shows that experiment \# 3 is the best experiment of nine experiments, besides that experiment \# 1 is the worst experiment. In experiment \# 3 , it is clear that $M R R$ has the largest value in nine experiments $(M R R=4160$ $\left.\mathrm{mm}^{3} / \mathrm{min}\right)$; $R a$ is $0.59 \mu \mathrm{m}$, smaller than the value of $R a$ in experiment \# 2, \# 6, \#8 and \# 9. Although $R a$ in experiment \# 3 are not the minimum values in nine experiments, but for the purpose of multi-objective optimization, it can be confirmed that experiment \# 3 is the "best" solution.

\section{Conclusion}

Equations An experimental process of milling 060A4 steel with an HSS cutting tool has been conducted in this study. The experimental matrix has been built by the Taguchi method with a total of nine experiments, in which spindle speed, feed rate and cutting depth have been selected as variations during the experiment. The effect of input parameters on surface roughness has been found. The PSI method has been used to solve the multiobjective optimization problem. A number of conclusions are drawm as follows:

- Feed rate is a parameter having a great effect on surface roughness, while spindle speed and cutting depth have a negligible effect on surface roughness.

- In order to simultaneously ensure the two criteria of milling process as the minimum surface roughness and 
the maximum $M R R$, spindle speed, feed rate and cutting depth are $538 \mathrm{rev} / \mathrm{min}, 130 \mathrm{~mm} / \mathrm{min}$ and $0.8 \mathrm{~mm}$, respectively.

- The PSI method has been first applied to solve the multi-objective optimization problem of the milling process in this study. This method also promises to be successful when applied to the multi-objective optimization in other machining processes.

- Determining the value of parameters of cutting parameters, parameters of cutting tools, parameters of machining materials, etc., to simultaneously ensure two or more objectives of the milling process is the content of next study of the authors in this article.

\section{Acknowledgment}

This work was supported by Thai Nguyen University of Technology.

\section{References}

1. T.V. Dich, N.T. Binh, N.T. Dat, N.V. Tiep, T.X. Viet, Manufacturing technology, Science and Technics (Publishing House, Ha Noi, 2003)

2. A. A. Thakre, International Journal of Emerging Technology and Advanced Engineering, 3, 226 (2013)

3. M. Prakash, L. T. Chavali, International Journal of Engineering Research \& Technology, 9, 783 (2020)

4. M. Kumar, M. S. Kaswan, International Journal of Technical Research, 5, 4 (2016)

5. P. V. Krishna, P. J. Reddy, T. Achyuth, K. V. S. Phani, Mukt Shabd Journal, 9, 3237 (2000)

6. S. S. Panshetty, R. R. Patil, P. V. Bute, J. B. Satpute, International Journal of Science Technology \& Engineering, 2, 130 (2016)

7. H. Shagwira, T. O. Mbuya, F. M. Mwema, M. Herzog, E. T. Akinlabi, Taguchi Optimization of Surface Roughness and Material Removal Rate in CNC Milling of Polypropylene + 5wt.\% Quarry Dust Composites, International Conference on Engineering for Sustainable World, 1107, 1-10, (2021)

8. D. P. Vansh, D. Patel, International Journal for Innovative Research in Science \& Technology, 4, 1 (2017)

9. H.C. Liao, Y.K. Chen, International Journal of Quality \& Reliability Maganement, 19, 825(2002)

10. A. R. Wisnuadi, R. W. Damayanti, E. Pujiyanto, Multi Response Optimization of Internal Grinding Process Parameters for Outer Ring using Taguchi Method and PCR-TOPSIS, AIP Conference Proceedings, 1931, 1, (2018)

11. P. Umamaheswarrao, D.R. Raju, KNS Suman, B.R. Sankar, Acta Mechanica Malaysia (AMM), 2, 28 (2019)

12. J. Kumar, R.K. Verma, FME Transactions, 48, 628 (2020)

13. P.B. Sagar, P.D. Pantanwane, B. Rajiv, Optimisation of hard turning of M42 steel using
PCR-Topsis method, 5th International \& 26th All India Manufacturing Technology, Design and Research Conference, IIT Guwahati, Assam, India, 325, 1( 2014)

14. A. Thanikasalam, J. Elanchezhian, International Journal of Advance Science and Technology, 29, 6927 (2020)

15. S.S. Sankar, M.V. Kumar Reddy, International Journal of Engineering and Advanced Technology, 8, 76(2019)

16. Dinh, L.C.,Science \& technology development, 19, 97 (2016)

17. M. Gangil, M. K. Pradhan, Materials Today: Proceedings, 5, 7486 (2018)

18. R. Bhuyan, B. Routara, Decision Science Letters, 5, 69(2016)

19. Kumar, G. V. A., Reddy, D. V. V., \& Nagaraju, N, i-Manager's Journal on Mechanical Engineering, 8, 39 (2018)

20. V. S. Gadakh, International journal of applied engineering research, 1, 743 (2011)

21. Mesran, R. K., Hondro, M., Syahrizal, A. P. U., Siahaan, R., Rahim, S., Student Admission Assesment using Multi-Objective Optimization on the Basis of Ratio Analysis (MOORA), 4th International seminar: Research for science, technology and culture, 1-7, 2017.

22. R. Attri, S. Grover, Journal of King Saud University - Engineering Sciences,(2013)

23. B. Vahdani, S. M. Mousavi, S. Ebrahimnejad, Journal of Intelligent \& Fuzzy Systems, 26, 393( 2014)

24. S. H.Sahir, J. Afriani, G. Ginting, B. Fachri, D. Siregar, R. Simbolon, L. Lindawati, M. Syarizal, S. Aisyah, M. Mesran, F. Fadlina, J. Simarmata, International Journal of Engineering \& Technology, 7, 260( 2018)

25. K. Maniya, M. G. Bhatt, Materials and Design, 31, 1785( 2010)

26. http://www.naradijurman.cz/case/dc419d018c36986 9.html

27. D. B. R. Tadeusz, Z. B. Edward, N.G. Allan R. H. Leslie, M. Wyatt, Manufacturing methods, Mechanical Engineer's Reference Book, 16, 16 (1994)

28. D. D. Trung, Tribology in Industry, 42, 658 (2020)

29. N. Van Du, N. Dang Binh, Design of experiment techniques, (Science and technics publishing House, Ha Noi, Viet Nam, 2011).

30. A. Dean, D. Voss, D. Draguljić, Design and Analysis of Experiments - Second Edition, (Springer, 2007) 